\title{
A suplementação com ácido linoléico conjugado reduziu a gordura corporal em ratos Wistar
}

\author{
Conjugated linoleic acid suplementation \\ decreased the body fat in Wistar rats
}

\author{
Adriana Prais BOTELHO' \\ Lilia Ferreira SANTOS-ZAGO' \\ Soely Maria Pissini Machado REIS² \\ Admar Costa de OLIVEIRA²
}

\section{R E S U M O}

O ácido linoléico conjugado, um conjunto de isômeros geométricos e de posição do ácido linoléico, vem sendo muito estudado devido ao seu efeito sobre a composição corporal, promovendo redução da massa gorda. O objetivo deste trabalho foi avaliar o efeito da suplementação com ácido linoléico conjugado sobre a composição corporal de ratos Wistar saudáveis em crescimento. Um total de 40 ratos, divididos em quatro grupos, foram suplementados diariamente durante três semanas com AdvantEdge ${ }^{\circledR}$ ácido linoléico conjugado (EAS ${ }^{\mathrm{TM}}$ ) nas concentrações 1,0\%, 2,0\% e 4,0\% sobre o consumo diário de dieta, constituindo, respectivamente, os grupos AE1, AE2 e AE4, e com ácido linoléico na concentração de $2 \%$ sobre o consumo diário de dieta, constituindo o grupo-controle. Os animais foram suplementados por meio de entubação orogástrica. Para a avaliação da composição corporal centesimal foi removido o conteúdo intestinal para obtenção da carcaça vazia. Em seguida, a carcaça foi congelada em nitrogênio líquido, fatiada, liofilizada, moída e armazenada a $-25^{\circ} \mathrm{C}$, até o momento das determinações de umidade, cinzas, proteína bruta e gordura. $\mathrm{O}$ grupo AE1 apresentou maior consumo de dieta e ganho de peso, mas não diferiu quanto à eficiência alimentar dos demais grupos $(p \leq 0,05)$. Em relação à composição corporal, constatou-se redução dos teores de gordura corporal dos grupos AE2 (11,2\%) e AE4 (11,6\%), quando comparados ao teor do grupo-controle (13,9\%). A suplementação com ácido linoléico conjugado nas concentrações de 2,0\% e 4,0\% sobre o consumo diário de dieta promoveu redução de gordura corporal de 18,0\% nos ratos Wistar.

Termos de indexação: ácido linoléico, suplementação, ganho de peso, ratos.

\section{A B S T R A C T}

Conjugated linoleic acid, a group of positional and geometric isomers of linoleic acid, has been greatly investigated due to its effect on body composition, mainly the reduction of body fat. The purpose of this study

\footnotetext{
1 Curso de Pós-Graduação em Alimentos e Nutrição, Faculdade de Engenharia de Alimentos, Universidade Estadual de Campinas. Campinas, SP, Brasil.

2 Departamento de Alimentos e Nutrição, Faculdade de Engenharia de Alimentos, Universidade Estadual de Campinas. Caixa Postal 6121, 13083-862, Campinas, SP. Correspondência para/Correspondence to: A.C. OLIVEIRA. E-mail: <admarco@fea.unicamp.br>.
} 
was to evaluate the effect of conjugated linoleic acid supplementation on the body composition of healthy, growing Wistar rats. Forty male Wistar rats were divided into 4 groups and supplemented daily for 3 weeks with AdvantEdge ${ }^{\circledast}$ conjugated linoleic acid (EASTM) at concentrations of 1.0\%, $2.0 \%$ and $4.0 \%$ of the daily feed intake, corresponding to groups AE1, AE2 and AE4, and with linoleic acid at 2.0\% (control) corresponding to group C. The animals were supplemented via a stomach tube. For the body composition analyses, the gut contents were removed to obtain the empty carcass weight. The carcasses were then frozen in liquid nitrogen, chopped, dried, ground and stored at $-25^{\circ} \mathrm{C}$, until analyzed for water, ash, protein and fat. The AE1 group showed higher feed intake and weight gain, but did not differ in food efficiency from the other groups ( $p \leq 0.05)$. In terms of body composition, body fat reduced in groups AE2 (11.2\%) and AE4 (11.6\%), as compared to the control (13.9\%). Conjugated linoleic acid supplementation at a rate of $2.0 \%$ and $4.0 \%$ with respect to the daily feed intake, decreased body fat by $18.0 \%$ in Wistar rats.

Indexing terms: linoleic acid, supplementary, weight gain, rats.

\section{N T R O D U Ç Ã O}

O ácido linoléico conjugado (CLA), um grupo de isômeros de posição e geométricos com duplas ligações conjugadas do ácido octadecadienóico (C18:2), é encontrado em pequenas quantidades em uma grande variedade de alimentos e estima-se a existência de 56 possíveis isômeros ${ }^{1,2}$. A discussão a respeito da suplementação com CLA tem sido acirrada, frente aos efeitos fisiológicos reportados por muitos grupos de pesquisa nos últimos anos. Sendo assim, são muitas as investigações no sentido de avaliar os efeitos benéficos do consumo de CLA, como alterações na composição corporal, redução da aterosclerose, prevenção e tratamento do diabetes mellitus tipo 2, potencialização da mineralização óssea, modulação do sistema imune e efeito antitrombogênico ${ }^{1}$. Possíveis efeitos adversos, como piora da resistência à insulina e aumento da suscetibilidade à autoxidação lipídica, também foram estudados ${ }^{3,4}$. O CLA pode ser originado no rúmen por meio da bioidrogenação incompleta de ácidos graxos poliinsaturados provenientes da dieta e também endogenamente, pela dessaturação do ácido graxo C18:1 trans 11 . $\mathrm{Na}$ bioidrogenação, o isômero cis9, trans 11 é o primeiro intermediário formado a partir do ácido linoléico pela $\Delta^{12}$ e $\Delta^{11}$ trans isomerase. Em seguida, ocorrem reduções das ligações cis, até C18:1 trans 11, que podem ainda ser reduzidas até C18:0. Na produção endógena do CLA, o ácido graxo C 18:1 trans 11 sofre dessaturação pela enzima $\Delta^{9}$ dessaturase presente na glândula mamária e no tecido adiposo 5 . Um dos efeitos mais estudados com relação à suplementação de CLA é sua capacidade em alterar a composição corporal, promovendo aumento da massa magra e redução da massa gorda em diferentes espécies, tais como: camundongos ${ }^{6,7}$, ratos $^{8,9}$, hamster ${ }^{10}$, $\operatorname{porcos}^{11,12}$, humanos ${ }^{13,14}$, entre outras. Os possíveis mecanismos de ação que explicam esse efeito são diminuição da proliferação e diferenciação de pré-adipócitos evidenciadas pela inibição do receptor ativado por proliferadores de peroxissoma gama (PPAR $\gamma)$, aumento do gasto energético, alteração da atividade das enzimas carnitina palmitoiltransferase e lipase lipoprotéica e da concentração de leptina ${ }^{15-19}$.

\section{MÉ T O D OS}

Foram utilizados 40 ratos machos saudáveis e recém-desmamados, da linhagem Wistar, provenientes do Centro Multidisciplinar de Investigação Biológica da Universidade Estadual de Campinas. Durante todo o período experimental os animais permaneceram em gaiolas de crescimento individuais consumindo água e dieta AIN93G ${ }^{20}$ com concentração de proteína de $12 \%{ }^{21}$ sob o sistema de livre acesso, sendo a temperatura e a umidade do ar controladas na faixa de $22 \pm 1^{\circ} \mathrm{C}$ e $60 \%-70 \%$, respectivamente, e ciclo de claro/escuro de doze horas. Após um período de sete dias de adaptação, os ratos foram divididos aleatoriamente em quatro grupos 
(controle e experimentais) e suplementados por 21 dias. O acompanhamento do ganho de peso e o consumo de dieta eram realizados a cada dois dias. Os grupos receberam ácido linoléico conjugado AdvantEdge ${ }^{\circledR}$ CLA (EAS ${ }^{\mathrm{TM}}$ ) nas concentrações $1 \%$, $2 \%$ e $4 \%$ sobre o consumo diário de dieta, constituindo, respectivamente, os grupos AE1, AE2 e AE4 (experimentais), e ácido linoléico na concentração de $2 \%$ sobre o consumo diário de dieta, constituindo o grupo C (controle). Os animais foram suplementados por meio de entubação orogástrica, utilizando seringa descartável de $1 \mathrm{~mL}$ e agulha de gavage. Ao final do experimento os animais foram mortos por deslocamento cervical e em seguida todo o trato gastrointestinal foi limpo e devolvido à carcaça ${ }^{6}$, que foi então congelada em nitrogênio líquido, fatiada, liofilizada, moída e armazenada a $-25^{\circ} \mathrm{C}$ até o momento das determinações de umidade segundo método 930.15, cinzas segundo método 942.05 e proteína bruta segundo método 954.01, todos descritos pela Association of Official Analytical Chemists $(A O A C)^{22}$. A determinação de gordura total foi feita pelo método de Soxhlet, conforme Lees ${ }^{23}$. Os teores de proteína, lípides, cinzas e umidade foram também determinados na dieta. Os dados foram submetidos à análise de variância ANOVA, seguida de teste de Tukey, com nível de significância de $5 \%$. O software utilizado para a análise foi o Statistical Analysis System (SAS). Este trabalho foi aprovado pela Comissão de Ética na Experimentação Animal (CEEA - IB/ Unicamp) - Protocolo n 564-1.

\section{RES U LTA DOS}

Os valores de consumo de dieta e ganho de peso estão expressos na Tabela 1, na qual se observa que apenas o grupo AE1 apresentou valores estatisticamente diferentes $(p \leq 0,05)$ em relação aos demais grupos, mas não diferiu quanto à eficiência alimentar.

Com relação à avaliação da composição corporal centesimal (Figura 1), constatou-se que os grupos AE2 e AE4 apresentaram teores de gordura corporal de 11,17 $\pm 0,79 \%$ e 11,62 $\pm 0,93 \%$, respectivamente, e o grupo-controle apresentou $13,9 \pm 1,23 \%$, o que corresponde, em relação ao grupo AE2, a uma redução de aproximadamente $20,00 \%$ da gordura corporal. Esses dados são similares aos resultados obtidos por Delany et al. ${ }^{24}$, que relataram uma redução de $30,00 \%$ da gordura corporal de camundongos após suplementação com CLA por 39 dias. Mais recentemente, Azain et al. ${ }^{25}$ também encontraram redução de 13,00\% a $30,00 \%$ da gordura retroperitoneal em ratas suplementadas com CLA por 35 dias. Outros trabalhos relatam reduções mais expressivas da gordura corporal, como o estudo realizado por Park et al. ${ }^{6}$, em que camundongos apresentaram redução de $60,00 \%$ da gordura corporal quando suplementados com 0,50\% de CLA durante 32 dias.

Vale ressaltar que o período de suplementação utilizado por esses autores foi superior ao empregado neste trabalho, o que pode justificar os maiores valores de redução de gordura corporal, e também que os modelos experimentais utilizados são caracterizados por acúmulo de gordura visceral e uma leve obesidade, diferentemente dos animais deste estudo.

Tabela 1. Valores médios \pm desvio-padrão $(n=10)$ do consumo de dieta, ganho de peso e eficiência alimentar dos ratos dos gruposcontrole e experimentais.

\begin{tabular}{|c|c|c|c|c|c|}
\hline \multirow{2}{*}{ Grupos } & \multicolumn{2}{|c|}{ Consumo (g) } & Ganho de peso (g) & \multicolumn{2}{|c|}{ Eficiência alimentar } \\
\hline & $M$ & DP & $M \pm D P$ & $\mathrm{M}$ & $\pm \mathrm{DP}$ \\
\hline $\mathrm{C}$ & 241,4 & $\pm 22,9^{\mathrm{a}}$ & $78,4 \pm 16,1^{a}$ & 0,32 & $\pm 0,04^{a}$ \\
\hline AE1 & 285,6 & $\pm 17,9^{\mathbf{b}}$ & $99,0 \pm 8,4^{b}$ & 0,35 & $\pm 0,02^{a}$ \\
\hline AE2 & 243,0 & $\pm 23,5^{a}$ & $83,4 \pm 13,0^{\mathbf{a}, \mathbf{b}}$ & 0,35 & $\pm 0,03^{a}$ \\
\hline AE4 & 230,0 & $\pm 23,8^{a}$ & $75,8 \pm 17,7^{a}$ & 0,32 & $\pm 0,04^{a}$ \\
\hline
\end{tabular}

Valores com letras iguais na mesma coluna não apresentam diferença significativa $(p>0,05)$ ao teste de Tukey. 


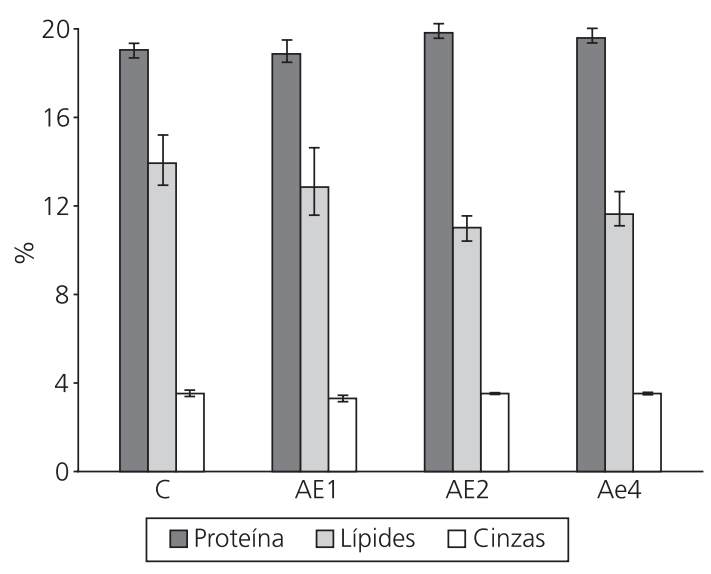

Figura 1. Composição corporal centesimal dos ratos dos grupós-controle e experimentais $(n=10)$.

Nota: $p \leq 0,05$ ao teste de Tukey.

As suplementações com ácido linoléico conjugado nas concentrações de $2 \%$ e $4 \%$ sobre o consumo diário de dieta reduziram a gordura corporal em ratos Wistar saudáveis em crescimento, indicando que a suplementação com $2 \%$ é economicamente mais viável. É importante destacar que a utilização de ratos em crescimento, neste trabalho, foi sustentada pela hipótese de que o CLA age sobre a lipogênese ${ }^{17}$. Trabalhos com períodos de suplementação mais extensos são necessários visando uma diminuição mais expressiva da gordura corporal, assim como um aumento de massa magra.

\section{AGRADECIMENTOS}

Ao Laboratório de Micronutrientes da Faculdade de Nutrição da Pontifícia Universidade Católica de Campinas pela utilização do liofilizador. À Fundação de Amparo à Pesquisa do Estado de São Paulo pelo auxílio financeiro (Processo $n^{\circ}$ 03/07648-4) e ao Conselho Nacional de Desenvolvimento Científico e Tecnológico pela bolsa concedida (APB) (Processo $\left.n^{\circ} 133874 / 2003-6\right)$.

\section{REFERÊ N CIAS}

1. Chouinard PY, Bauman BA, Baumgard MA. An update on conjugated linoleic acid. In:
Procceedings of the Cornell Nutrition Conference Feed Manufactory. Ithaca (NY); 1999. p.93-101.

2. Yurawecz MP, Sehat N, Mossoba MM, Roach JAG, Kramer JKG, Ku Y. Variations in isomer distribution in commercially available conjugated linoleic acid. Lipids. 1999; 101:277-82.

3. Yamasaki M, Mansho K, Mishima H, Kimura G, Sasaki M, Kasai M, et al. Effect of dietary conjugated linoleic acid on lipid peroxidation and histological change in rat liver tissues. J Agric Food Chem. 2000; 48(12):6367-71.

4. Risérus U, Vessby B, Ärnlöv J, Basu S. Effects of cis-9, trans-11 conjugated linoleic acid supplementation on insulin sensitivity, lipid peroxidation, and proinflammatory markers in obese men. Am J Clin Nutr. 2004; 80(2):279-83.

5. Corl BA, Baumgard LH, Dwyer DA, Griinari JM, Philips BS, Bauman DE. The role of delta-9-desaturase in the production of cis-9, trans-11 CLA and other delta-9-desaturase fatty acids in milk fat. J Dairy Sci. 2000; 83 Suppl 1:S167.

6. Park Y, Albright KJ, Liu W, Storkson JM, Cook ME, Pariza MW. Effect of conjugated linoleic acid on body composition in mice. Lipids. 1997; 32(8): 853-8.

7. West DB, Delany JP, Camet PM, Blohm F, Truett AA, Scimeca J. Effects of conjugated linoleic acid on body composition fat and energy metabolism in the mouse. Am J Physiol. 1998; 275(3 Pt 2):R667-72.

8. Houseknecht KL, Vanden HJP, Moya-Camarena SY, Portocarrero CP, Peck LW, Nickel KP. Dietary conjugated linoleic acid normalizes impaired glucose tolerance in the Zucker diabetic fatty fa/fa rat. Bioch Biophys Res Comm. 1998; 244(3): 911-7.

9. Sisk MB, Hausman DB, Martin RJ, Azain MJ. Dietary conjugated linoleic acid reduces adiposity in lean but not obese Zucker rats. J Nutr. 2001; 131(6):1668-74.

10. de Deckere EAM, van Amelsvoort JM, McNeill GP, Jones P. Effects of conjugated linoleic acid (CLA) isomers on lipid levels and peroxisome proliferation in the hamster. Br J Nutr. 1999; 82(4):309-17.

11. Cook ME, et al. Feeding conjugated linoleic acid improves feed efficiency and reduces whole body fat in pigs. FASEB J. 1998; 12:A836.

12. Ostrowska E, Muralitharan M, Cross RF, Bauman DE, Dunshea FR. Dietary conjugated linoleic acid increase lean tissue and decrease fat deposition in growing pigs. J Nutr. 1999; 129(11):2037-42.

13. Berven G. Safety of conjugated linoleic acid (CLA) in overweight or obese human volunteers. Eur J Lipid Sci Technol. 2000; 102:455-62. 
14. Blankson $H$, Stakkestad JA, Fagertun $H$, Thom $E$, Wadstein J, Gudmundsen O. Conjugated linoleic acid reduces body fat mass in overweight obese humans. J Nutr. 2000; 130(12):2943-8.

15. Granlund L, Juvet L, Pedersen J, Nebb H. Trans-10, cis-12-conjugated linoleic acid prevents triacylglycerol accumulation in adipocytes by acting as a PPARg modulator. J Lipid Res. 2003; 44(8): 1441-52.

16. Belury MA. Dietary conjugated linoleic acid in health: physiological effects and mechanismis of action. Ann Rev Nutr. 2002; 22:505-31.

17. Brodie AE, Manning VA, Ferguson KR, Jewell DE, $\mathrm{Hu}$ CY. Conjugated linoleic acid inhibits differentiation of pre- and post- confluent 3T3-L1 preadipocytes but inhibits cell proliferation only in preconfluent cells. J Nutr. 1999; 129(3): 602-6.

18. Rahman SM. Effects of conjugated linoleic acid on serum leptin concentration, body-fat accumulation, and $\beta$-oxidation of fatty acid in OLETF rats. Nutrition. 2001; 17(5):385-90.

19. Medina EA. Conjugated linoleic acid supplementation in humans: effects on circulating leptin concentrations and appetite. Lipids. 2000; 35(7):783-8.

20. Reeves PG, Nielsen FH, Fahey GCJ. AIN-93 Purified diets for laboratory rodents: final report of the
American Institute of Nutrition Ad Hoc Writing Committee on the Reformulation of the AIN-76A rodent diet. J Nutr. 1993; 123(11):1939-51.

21. Goena M, Marzo F, Fernández-González L, Tosar A, Frühbeck $\mathrm{G}$, Santidrián $\mathrm{S}$. Effect of the raw legume Vicia ervilha on muscle and liver protein metabolism in growing rats. Rev Esp Fisiol. 1989; 45 Suppl: S55-9.

22. Association of Official Analytical Chemists. Official methods of analysis of AOAC 16th ed. International. Washington (DC): AOAC International; 1995. v.1.

23. Lees R. Manual de análisis de alimentos. Laboratory handbook of methods of food analysis. Zaragoza: Acribia; 1979.

24. Delany JP, Blohm F, Truett AA, Scimeca JA, West DB. Conjugated linoleic acid rapidly reduces body fat content in mice without affecting energy intake. Am J Physiol. 1999; 276(4 Pt2):R1172-9.

25. Azain MJ, Hausman DB, Sisk MB, Flatt WP, Jewell DE. Dietary conjugated linoleic acid reduces rat adipose tissue cell size rather than cell number. J Nutr. 2000; 130(6):1548-54.

Recebido para publicação em 26 de julho de 2004 e aceito em 18 de novembro de 2004. 